\title{
Small and Medium-Sized Enterprises in Rural Areas of the Czech Republic and Their Approach to Management Auditing
}

\author{
Daniel Raušer ${ }^{1, *}$ \\ ${ }^{1}$ Institute of Technology and Business, Faculty of Corporate Strategy, Nemanická 436/7, 37010 České Budějovice, Czech Republic
}

\begin{abstract}
Regarding small and medium-sized enterprises (SMEs) and their conditions in the present business environment, it is determinative for them to be prosperous and ambitious. In order to achieve their defined goals, such enterprises are advised to conduct periodical marketing environmental analyses and various audits. However, an audit process that examines overall enterprise management and measures its performance, i.e. management auditing, tends to be overlooked at times or mistaken for other activities. Related research involving Czech SMEs located in rural areas and operating in diverse industries discovered that management audit process capabilities, specifically in terms of organization and resources, are not fully utilized resulting in the enterprises' lower competitiveness. In connection with broader assessment of enterprise management systems, the objective of this paper consists in introducing a particular sub-model titled "Comprehensive and Individual Resource Analysis", which finalizes the previously developed and published "Two-Stage 7S Evaluation Model" [1]. Implementing the eventually completed model of management auditing on a regular basis would allow the SMEs to remove faults (and raise efficiencies) in their management processes, and enhance their enterprise value in the domestic and international markets. Keywords: management auditing; small and medium-sized enterprises; rural areas; comprehensive and individual resource analysis; management system evaluation
\end{abstract}

\section{Introduction}

Nowadays, perhaps all business enterprises, especially small and medium-sized enterprises (SMEs) based outside urban areas, aim for sustainability and profitability supplemented by taking competitive advantages over other enterprises. The most significant aspect of such advantages may be seen, for instance, in thorough knowledge of enterprise environment and customer needs and wishes [2], an efficient use of enterprise management systems [3], internal stability [4], a quality workforce [5], or quality marketing and advertising [6]. Also, enterprises should make regular analyses of their internal environment and that is where management auditing may be used as a pivotal instrument. Furthermore, the main effort of enterprises (including the above SMEs) should reside in continuous improvement of their management systems. That implies recognizing the systems' current state (with their positives and negatives) and possibly designing new or modified systems, which may be viewed as the primary content of the management audit [7]. As well as that, it should be an independent and objective review that assists enterprises in reaching their targets by presenting a systematic, methodical approach that would inspect and help to boost the efficiency of management processes. Moreover, management auditing contributes to discovering problematic area(s) within enterprises, reducing their effective management [8], and supplies enterprise managers with information on the style, quality and manner of their management [9]. However, a number of research papers have shown that mostly SMEs have not been using management auditing in the same frequency and intensity, as opposed to other audits (e.g. environmental, financial, personnel, sales, tax audits, etc.), and the content and purpose of management audits have often been mistaken. Moorthy et al. [10], Botez [11], Aschauer et all. [12] and Ma'ayan, Carmeli [13] all state that management audits tend to be either omitted or replaced with internal audits in relation to audited areas (such as management, production, marketing and finance). Hrušková [14] claims that management auditing is seldom performed by SMEs, and is even being confused with marketing auditing due to the use of identical analyses (e.g. SWOT analysis, the IFE matrix and the EFE matrix) in order to assess strengths and weaknesses. Vágner [15] points to some confusion between management auditing and internal controlling given the similarity of provided services (consulting, information and advisory activities or methodologies on suitable enterprise management). Nevertheless, management as such, should indeed be regarded as the essential area in terms of management auditing. Depending on their discretion, however, managers or auditors may then concentrate on other areas, e.g. human resources, marketing, production, finances and IT systems, as advised by Wheelen, Hunger [4]. In the opinion of Majernik et al. [16], there should also be a focus on quality and sales, with special attention being drawn to risk management as

\footnotetext{
*Corresponding author: raudan@mail.vstecb.cz
} 
part of the management orientation. The same viewpoint is held by Stojanovic et al. [17] and Rivera et al. [18]. Other authors, e.g. Ujwary-Gil [19], Pascual, Kumar [20] note that certain efficiency of used resources is to be ultimately considered as well.

\section{Methodology}

An electronic questionnaire survey, structured interviews and model development were used in this paper. The survey (and the related data processing) was carried out between September 2017 and December 2019 and involved only SMEs that are situated in rural areas of the Czech Republic and operate in various industries (e.g. agriculture, automotive, building, engineering, hospitality, textiles, etc.). At the author's request, an alphabetical list of such SMEs officially registered in each of the country's 14 administrative regions had been sent to him from the Association of Small and Medium-Sized Enterprises and Crafts CZ. Since the vast majority of micro-enterprises (with up to 10 employees) do not conduct management audits, as has been confirmed by previous research [1], they were automatically excluded from the survey. Subsequently, enterprises, whose contact details could be found online, were approached via email and members of their management were asked to fill in an electronic questionnaire, comprising three questions and three follow-up questions, and submit their answers afterwards. The aim was to find out whether: a) the SMEs perform management audits (in their true sense, i.e. assessment of the current state of enterprise management systems) and/or other audits (and if they do, then which?); b) the SMEs develop and/or employ any aids (analyses, models, etc.) for assessing their management systems and/or available resources (and if they do, then which?); c) the SMEs consider themselves to be competitive (and if they do, then whether and how do they succeed in keeping up their competitive strategy or advantages?). Next, the survey was supplemented by structured interviews with a group of 12 auditing professionals (with $10+$ years of experience) that the author has collaborated with before. The purpose was to learn about their supposed knowledge of management auditing and potentially gather some more valuable facts or details about the issue. As for model development, the primary objective was to extend the already compiled "Two-Stage 7S Evaluation Model" [1] by proposing an additional sub-model (titled "Comprehensive and Individual Resource Analysis"), which would constitute the third stage in management audit implementation and would be a further action connected with two preceding submodels. To be brief, principles of the first stage are included in the "7S Adaption" sub-model (as based on the 7S McKinsey Framework), i.e. a proposed analysis of enterprise management from the standpoint of efficiency and effectiveness. Here, managers or auditors are able to detect strengths/weaknesses in view of the given enterprise management. That is followed by principles of the second stage incorporated in the "Application IFE - 7S Matrix" submodel (as based on the IFE Matrix), i.e. an expanded enterprise management analysis linked to assessing specific evaluation factors or their indicators with regard to internal stability within the entire enterprise management. Here, it may be determined whether strengths prevail over weaknesses or vice versa. Additionally, since resources are integral to enterprises and their operations and may facilitate an improvement in their market competitiveness, the third stage principle (reflected in the intended sub-model) is a further analysis (evaluation) of enterprises in relation to their resource utilization systems, hence being the extension of the above Evaluation Model (and specifically referring to the following characteristics: "Factors - Systems - Evaluation Indicators - System of using company (enterprise) resources - Evaluation Questions - Does the enterprise use an optimal combination of its resources?"). Having been completed, the entire model could possibly be presented as a "Three-Stage Evaluation Model of Enterprise Management", and on its examining, managers themselves may ultimately decide on the model's applicability and appropriateness for the respective enterprises and their related activities.

\section{Results and Discussion}

The number of approached SMEs in rural areas of the Czech Republic eventually totalled 1066. Surprisingly, and contrary to the author's expectations, a considerable number (862, i.e. $80,86 \%$ ) of them participated in the survey by responding to the above questions. Time-consuming data processing was therefore required, yet it conduced to generate a fairly representative sample being of a highly informative nature, where the highest response (return) rate was reported for SMEs in the Prague Region (17,2\%), the Liberec Region (14,8\%) and the Karlovy Vary Region (13,6\%), whereas the lowest response (return) rate was reported for SMEs in the Ústí Region (4,3\%), the Moravia-Silesia Region (2,7\%) and the Vysočina Region (1,5\%). Considering the actual results, the survey found that only $126(14,6 \%)$ of the SMEs (hereinafter referred to as "enterprises") carry out management audits as such. The survey, as well as the interviews, also proved that 394 (i.e. $45,7 \%$ ) out of 862 enterprise managers, and 4 out of 12 auditors respectively, do not frequently distinguish management audits from several other audits. To further add to this, the managers perceive the management audit's concept as that of a personnel audit or an audit of managerial characteristics and skills, or even exchange it for an internal audit, whereas the auditors proffer the management audit as a personnel audit when dealing with different enterprises. Moreover, despite the fact that 342 enterprises (i.e. 39,6\%) do have analyses of the current state of their management systems prepared and implemented, the results are not summarized, but are assessed rather individually, which does not obviously provide the enterprises with comprehensive evaluations. Specifically, the analyses include SWOT analysis, balanced scorecards, process analysis and internal benchmarking. In spite of that, quite a large number of the managers (449, i.e. 52\%) stated that every so often the enterprises managed by them struggled to maintain their competitiveness, while not completely using their available resources, which affects the functioning and market position 
of the enterprises. Lastly, and perhaps surprisingly, the survey clearly indicated that 96 managers (i.e. 28\%) learnt about the management audit for the first time only from the paper's author, and were not even aware of its content or purpose. Conversely, the highest number of performed enterprise audits involved mandatory audits, particularly tax audits, followed by financial, personnel, cost, quality and internal audits. Aside from that, it should be added that the data collected were contributory factors for the author in his preparing the considered resource sub-model (and finishing the full model) and verified the validity of his choice of their development.

As regards the survey results together with findings from the interviews, it is recommended that (not only) the above enterprises conduct management auditing on a regular basis. That may be effected by the aforementioned "Two-Stage 7S Evaluation Model" that has been generated as the main framework in terms of using a suitable systemic approach as well as a standardized procedure, thereby allowing management audit implementation. However, any attempt to do so should largely depend on the willingness of the enterprises, or members of their management, and also on making a goal-directed effort and taking a problem-solving perspective to try and tackle the current situation in a particular enterprise. First, in order for the model to be genuinely applicable, and to fulfill the essence of management auditing (i.e. to evaluate the present state of enterprise management systems) as well as the systemic approach principle, the author believes that basic managerial questions presented in Table 1 are to be acknowledged, answered and discussed by enterprise managers who should realize which areas need to be analyzed as part of management auditing. Additionally, answering the questions is the first step (and simultaneously the basis) of the entire model and should be helpful in guiding the managers (and individual enterprises) to correct answers or solutions. Apart from that, the managerial questions may serve as precautions not to leave out any factors in view of sustainability and market success (for more details, see Píchová, Raušer, [1]).

Table 1. Managerial questions and factors

\begin{tabular}{|l|l|}
\hline Managerial Questions & Factors based on the 7S Model \\
\hline What does the enterprise want to achieve and how does it want to achieve it? & Strategy \\
\hline What staff and composition are needed in the enterprise? & Staff \\
\hline What abilities and skills does every employee need to have? & Skills \\
\hline What will be the hierarchical structure of selected employees? & Structure \\
\hline Which style of management should be used in the enterprise? & Style \\
\hline What systems are necessary to be used in the enterprise? & Systems \\
\hline Are all employees well aware of the enterprise events and happenings? & Shared values \\
\hline
\end{tabular}

Source: Author.

Then, having answered the questions and evaluated the first stage as well as the second stage results, managers may consequently advance to the third stage, i.e. an analysis (or assessment) of enterprise resources (tangible, intangible, financial, human). That is embodied by the following resource sub-model, i.e. the "Comprehensive and Individual Resource Analysis", whose first section includes comprehensive assessment of resources (Table 2), whilst the second section concerns individual assessment of resources (Table 4), with both sections holding the same importance.

Table 2. Comprehensive assessment of resources

\begin{tabular}{|c|c|c|c|c|c|}
\hline \multirow{2}{*}{ Category } & \multirow{2}{*}{$\begin{array}{c}\text { Category } \\
\text { Significance: } \\
\text { expressed by } 1,2 \text { or } 3\end{array}$} & \multicolumn{4}{|c|}{ Evaluation Indicators (Relevance): expressed by *, $+, \mathbf{x},-$ or 0} \\
\hline & & Tangible & Intangible & Financial & Human \\
\hline \multicolumn{6}{|c|}{ Resource Originality } \\
\hline \multicolumn{6}{|c|}{ Resource Availability } \\
\hline \multicolumn{6}{|c|}{ Resource Sustainability } \\
\hline \multicolumn{6}{|c|}{ Resource Flexibility } \\
\hline \multicolumn{6}{|c|}{ Resource Substitutability } \\
\hline \multicolumn{6}{|c|}{ Resource Importance } \\
\hline $\begin{array}{l}\text { Comprehensive } \\
\text { Assessment }\end{array}$ & -- & Aggregate Score & Aggregate Score & Aggregate Score & Aggregate Score \\
\hline \multicolumn{6}{|c|}{$\begin{array}{l}\text { Note 1: Category Significance is evaluated as follows: } \\
1=\text { high significance; } 2 \text { = average significance; } 3=\text { low significance. }\end{array}$} \\
\hline \multicolumn{6}{|c|}{$\begin{array}{l}\text { Note 2: Evaluation Indicators are assigned according to their relevance, where: } \\
\text { * denotes very high originality, very easy availability, very simple sustainability, very high flexibility, very easy substitutability, very } \\
\text { high importance; } \\
\text { + denotes high originality, easy availability, simple sustainability, high flexibility, easy substitutability, high importance; } \\
\text { x denotes low originality, difficult availability, difficult sustainability, poor flexibility, difficult substitutability, low importance; } \\
\text { - denotes very low originality, very difficult availability, very difficult sustainability, very poor flexibility, very difficult } \\
\text { substitutability, very low importance; } \\
\mathbf{0} \text { denotes zero (i.e. no) originality, availability, sustainability, flexibility, substitutability, importance. }\end{array}$} \\
\hline
\end{tabular}




\section{Source: Author.}

The table demonstrates that the comprehensive section encompasses evaluations of resources regarding their originality, availability, sustainability, flexibility, substitutability and importance (the categories generated by the author). Initially, each category is evaluated in view of its significance for a certain enterprise (see Note 1), which is followed by assessment of given resources in relation to the evaluation indicators (see Note 2). Eventually, there is a summary of results respecting the following simple formula: Significance $x$ Relevance

As a result, the above assessment may therefore determine whether resources the enterprise makes use of appear to be relevant or significant for it or not. From such a viewpoint, the author outlines the classification of enterprise resources into three types (classes) depending on their total number of gained points (or scores), as illustrated in Table 3.

Table 3. Scores of comprehensive assessment of resources

\begin{tabular}{|c|c|c|c|c|c|c|c|c|}
\hline \multicolumn{2}{|c|}{ Significance } & \multicolumn{2}{|c|}{ Relevance } & \multirow[b]{3}{*}{ Category } & \multirow{2}{*}{\multicolumn{4}{|c|}{$\begin{array}{c}\text { Comprehensive Assessment } \\
\text { Tally of Aggregate Scores }\end{array}$}} \\
\hline \multirow[b]{2}{*}{ 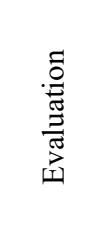 } & \multirow[b]{2}{*}{. } & \multirow[b]{2}{*}{$\begin{array}{l}\text { 品 } \\
\text { हे } \\
\text { ह }\end{array}$} & \multirow[b]{2}{*}{$\stackrel{\mathscr{n}}{. !}$} & & & & & \\
\hline & & & & & 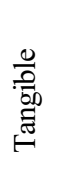 & 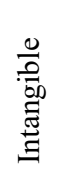 & 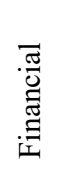 & 龸 \\
\hline 1 & 3 & $*$ & 4 & Originality & & & & \\
\hline 2 & 2 & + & 3 & Availability & & & & \\
\hline 3 & 1 & $\mathrm{x}$ & 2 & Sustainability & & & & \\
\hline & & - & 1 & Flexibility & & & & \\
\hline & & 0 & 0 & Substitutability & & & & \\
\hline & & & & Resource Importance & & & & \\
\hline & & issific & of $R$ & Classes I. - III. & & & & \\
\hline & & & & tual Comprehensive Assess & & & & \\
\hline & ce $\mathrm{C}$ & icatio & asses & Categorization of Classes & & & oints & \\
\hline & & & & Crucial Resource & & & & \\
\hline & & & & Influential Resource & & & & \\
\hline & & & & Substitutable Resource & & & & \\
\hline
\end{tabular}

Source: Author.

To be more specific, the first type, i.e. the crucial resource class, represents a resource (resources) vital for continuous operations of the enterprise. The resource(s) are utilized in an adequate amount and form, cannot be substituted by any other resource(s), and manager(s) of the enterprise are strongly recommended to retain the resource(s) in the long term. The second type, i.e. the influential resource class, contains a resource (resources) which have a great effect on running the enterprise, but which are not extremely important. The resource(s) are utilized only to a certain extent, cannot always be fully involved in enterprise activities, and manager(s) of the enterprise are advised to consider either maintaining the resource(s) in their existing amount and form, or decreasing their amount, or even altering their present form. Lastly, the third type, i.e. the substitutable resource class, includes a resource (resources) that are likely to be useful for the enterprise, yet they may not be so necessary and hence could be replaced. Furthermore, since assessing resources in terms of their relevance and significance is anticipated to be subjective from the manager's/managers' perspective, the author suggests a two-step evaluation in that respect. The first step could be seen as assessment of a comprehensive resource analysis performed individually by each manager of the enterprise (and auditors), whereas the second step could reside in assessing the comprehensive analysis carried out in mutual brainstorming.

Finally, when taking account of the second section, i.e. individual assessment of resources, the author proposes that related parameters stated in Table 4 are allowed for tangible, intangible, financial and human resources within the enterprise. The parameters only exemplify perhaps the most elementary features while conducting the analysis, and may be naturally and gradually amended in accordance with conditions or demands given by managers and/or auditors. However, it should be generally accepted for the resources and their corresponding parameters to be observed and evaluated throughout the entire process. 
Table 4: Individual assessment of resources

\begin{tabular}{|l|l|}
\hline Resources & Parameters \\
\hline Tangible & $\begin{array}{l}\text { Age of assets and machinery; Flexibility of assets and machinery; Technical conditions of assets and } \\
\text { machinery; Reliability of machinery; Production capacity of machinery; Material provision. }\end{array}$ \\
\hline Intangible & $\begin{array}{l}\text { Innovative development - patent or trademark development; The level of generated know-how; The level of } \\
\text { image among customers and the general public; The level of information security; The level of software } \\
\text { security used. }\end{array}$ \\
\hline Financial & $\begin{array}{l}\text { Balance of capital structure used - in terms of ownership and time; Trends - profit, cash flow, receivables } \\
\text { and payables; Trends - ratios of financial analysis and indicators based on cash-flow, used methods/styles of } \\
\text { financing. }\end{array}$ \\
\hline Human & $\begin{array}{l}\text { Number of employees - more detailed allocations to workers, administrative staff and managers; Employee } \\
\text { training and qualifications, experience, fluctuation, motivation preferences; Trust in employees; The level of } \\
\text { delegating authority to subordinate workers. }\end{array}$ \\
\hline $\begin{array}{l}\text { Overall } \\
\text { Assessment }\end{array}$ & $\begin{array}{l}\text { a) Assessment of Composition and Structure of Resources; b) Assessment of Balance and Combination of } \\
\text { Resources; c) Assessment of Intensity of Using Resources. }\end{array}$ \\
\hline
\end{tabular}

Source: Author.

In addition to that, it should be noted that (during the entire analysis) managers/auditors ought to be aware of all resources introduced into production as inputs and focus on their appropriate allocation. Concentrating only on resources the enterprise possesses (which may referred to as resources in the narrow sense) would not be desirable. Thus, similar attention should also be drawn to resources that cannot be possessed (e.g. relations with employees, customers, suppliers, creditors or business partners). They may be regarded as resources in the broader sense since they can become necessary and significant elements within the scope of the enterprise's advantages over competitors provided that such resources are efficiently utilized and mutually complemented, which should be under observation as well.

\section{Conclusion}

Business enterprise planning should be directed towards sustainable development conditioned, inter alia, by internal stability and efficient use of enterprise management systems. In order to determine their current form, management auditing may serve as a valuable assessment indicator. However, as emerged from the extensive electronic inquiry related to small and medium-sized enterprises (SMEs) in rural areas of the Czech Republic, such an approach to auditing either fails to be noticed or is substituted for divergent types of audits. It also transpired that accessible resources used within the SMEs do not reach their full potential, which interferes with enterprise operations and overall performance. In their effort to rectify the issues, (not only) the SMEs may implement management auditing according to the systemic procedure specified in this paper, where the "Comprehensive and Individual Resource Analysis" sub-model was put forward. It complements the formerly introduced "Two-Stage 7S Evaluation Model" by representing the third stage, and therefore meets the objective of this paper. Although each stage may be performed separately and more frequently, the completed model enables regular application with regard to assessing the current state of enterprise management, helping to increase competitiveness of enterprises as well as their position in the domestic and international markets, and raising awareness of management auditing among managers and other professionally engaged individuals.

\section{References}

1. R. Píchová, D. Raušer, Management audit as a tool for managing small and medium-sized enterprises. Proceedings of the $7^{\text {th }}$ International Conference on Management on "Managerial trends in the development of enterprises in globalization era”. (2017)

2. M. E. Porter, Competitive advantage: Creating and Sustaining Superior Performance. New York: Free Press (1985)

3. P. F. Drucker, Management challenges for the $21^{\text {st }}$ century. New York: Harper Business (1999)

4. T. L. Wheelen, D. J. Hunger, Strategic management and business policy: concepts and cases. $13^{\text {th }}$ ed. Upper Saddle River: Prentice Hal (2012)

5. M. Armstrong, Armstrong's handbook of strategic human resource management. $6^{\text {th }}$ ed. London: Kogan Page (2016)

6. P. T. Kotler, K. L Keller, Marketing Management. $15^{\text {th }}$ ed. Boston: Pearson (2016)

7. P. K. H. Spencer, Internal Auditor at Work. Hoboken: John Wiley (2004)

8. J. Truneček, Interní manažerský audit [Internal management audit]. Praha: Professional Publishing (2004) 
9. A. Chambers, G. Rand, The Operational Auditing Handbook: Auditing Business and IT Processes. $2^{\text {nd }}$ ed. Hoboken: John Wiley (2010)

10. M. K. Moorthy, et al., The impact of information technology on internal auditing. African Journal of Business Management. 5, 3523-3539 (2011)

11. D. Botez, Internal Audit and Management Entity. Procedia Economics and Finance. 3, 1156-1160 (2012)

12. E. Aschauer, A. Moro, M. Massaro, The auditor as a change agent for SMEs: the role of confidence, trust and identification. Review of Managerial Science. 95, 339-360 (2015)

13. Y. Ma'ayan, A. Carmeli, Internal audits as a source of ethical behaviour, efficiency and effectiveness in work units. Journal of Business Ethics. 137, 347-363 (2015)

14. D. Hrušková, Marketing audit and its impact on business performance. Conference on Current Problems of the Corporate Sector. 219-223 (2015)

15. L. Vágner, Controlling as an international economic tool. Proceedings of the $15^{\text {th }}$ International Scientific Conference on Globalization and its Socio-Economic Consequences. 829-833 (2015)

16. M. Majerník, N. Daneshjo, R. K. Stofkova, G. Sanciova, Integrated auditing of enterprise management systems in a globalized environment. Proceedings of the $16^{\text {th }}$ International Scientific Conference on Globalization and its Socio-Economic Consequences. 1261-1269 (2016)

17. T. Stojanovic, M. Andric, Internal auditing and risk management in corporations. Strategic management, 21, 31$42(2016)$

18. D. E. Rivera, A. S. Villar, M. R. M. Pino, Towards the Concept of Risk Approach in the audit integrated management system. Quality - Access to Success, 17, 41-47 (2016)

19. A. Ujwary-Gil, The concept and stages of the audit of intangible resources: A network approach. Proceedings of the $17^{\text {th }}$ European Conference on Knowledge Management. 916-925 (2016)

20. D. G. Pascual, U. Kumar, Maintenance Audits Handbook. Boca Raton: CRC Press (2016) 